\title{
KULEUYEN
}

CENTER FOR ECONOMIC STUDIES

DISCUSSION PAPER SERIES DPS15.11

MAY 2015

Tax and regulatory policies for European Transport - getting there, but in the slow lane

Bruno DE BORGER \& Stef PROOST

Energy, Transport and Environment

Faculty of Economics And Business 


\section{Tax and regulatory policies for European Transport - getting there, but in the slow lane ${ }^{1}$}

Bruno De Borger (UAntwerpen) and Stef Proost (KULeuven)

August 18, 2015

\section{Abstract}

This paper reviews policy developments in the EU transport sector. The EU has successfully introduced the external cost concept into policy thinking. In the policy orientations, there has been too much emphasis on climate and energy objectives. Also modal share objectives are popular among policy makers but are not a good guideline for transport policies.

The transition from high fuel taxes to distance charges has begun for trucks, but the charges need to be differentiated according to place and time. The same transition will also develop for cars, as soon as implementation costs have been reduced and public acceptance has improved.

EU transport policy priorities can be to allow and promote the progressive substitution of high diesel and gasoline taxes by other car and truck user charges that depend on place and time, to scale back overambitious implementation of biofuel and electric car policies and re-orient resources to R\&D for cleaner vehicles, to efficiently regulate distance charges for trucks and to assure an unbiased assessment of infrastructure investment needs.

Member country priorities can be to move away from high vehicle ownership and fuel taxes to local congestion charges; the extra burden on motorists might be offset by scaling back vehicle excise taxes and to complement the introduction of road pricing with peak-load pricing for public transport.

\footnotetext{
${ }^{1}$ We thank lan Parry for several rounds of detailed suggestions, and Herman Vollebergh, Kurt Van Dender and the participants of the CESIfo/EC/IMF/PBL conference on "Energy Tax and regulatory policy in Europe: reform priorities and research needs" (Munich, nov 2014) for useful comments on a first draft. We are grateful to ElBurs program for financial support and to Chau Man Fung for research assistance.
} 


\section{Introduction}

This policy paper will concentrate on road transportation, and more specifically on the role of road transport pricing, taxation and regulation. Policies that focus on other transport modes and on competition policy issues will be discussed only occasionally. We also disregard largely endogenous location of activities, which is an important long term dimension of urban development

We know from the analytical literature what reforms are most needed in the area of road pricing and taxation. These reforms require partially moving away from fuel and vehicle taxes towards car and truck user taxes that depend on place and time of use to more effectively mitigate congestion - often the most severe externality. Making this policy switch acceptable and implementing such pricing policies at the right policy level are the main policy challenges for the near future.

A brief overview is as follows. In Section 1, we start by putting in perspective the different policy issues, the main external costs, the policy objectives and the main tax and regulatory instruments currently used. Moreover, we briefly review EU-policy developments over the last 20 years. The next sections focus on passenger transport (Section 2) and freight transport policies (Section 3), respectively. A final section concludes.

\section{Main policy issues and developments over the past 20 years}

The last 50 to 60 years (from the 1958 Treaty of Rome onwards), a process of EU-integration and enlargement from 6 member countries to the current 28 countries took place. For the transport sector, this integration has strongly increased the volume of both freight and passenger transport; road transport is by far the dominant mode. The integration has necessitated competition policies for the freight transport sector (for example, allow trucks to operate in all countries), some fuel tax harmonization for diesel and gasoline to curb tax competition ${ }^{2}$, and regulation of toll regimes to avoid overcharging of through traffic. Moreover, as transport equipment and services are important inputs in production, these two markets have been deregulated and opened up for competition, and they have been re-regulated to achieve EU-wide environmental objectives like climate change and air pollution.

\subsection{Transport activity and its external costs}

Table 1 puts the relative importance of different transport modes and their external costs in perspective. A brief overview of how these figures were calculated in given in Appendix. As already noted, road transport is still the dominant mode of transportation with a market share of some $75 \%$ for passengers and $72 \%$ for inland freight

\footnotetext{
${ }^{2}$ Although fuel tax floors imposed at the EU level through the Energy Tax Directive are generally not binding, economic theory and casual evidence suggest they increase tax rates even in countries where they are not binding (as countries react to a reduced risk of tax competition). See for example Parry and Vollebergh (this volume).
} 
transport ${ }^{3}$. Airplanes, cars and trucks use almost exclusively oil products and are the most carbon intensive activities in the transport sector.

\begin{tabular}{|c|c|c|c|c|c|c|c|}
\hline & \multicolumn{4}{|c|}{$\begin{array}{l}\text { Passengers (€ct/vkm for cars and buses and €ct/tkm or pkm for rail } \\
\text { and air) }\end{array}$} & \multicolumn{3}{|c|}{ Freight $(€ c t / v k m$ for trucks and $€ c t / t k m$ for rail) } \\
\hline & \multicolumn{2}{|c|}{ Urban (20\%) } & \multicolumn{2}{|c|}{ Medium to long distance $(80 \%)$} & local & \multicolumn{2}{|c|}{ Medium to long distance } \\
\hline & Cars (70\%) & Other (30\%) & Cars $(80 \%)$ & Rail, air (20\%) & Trucks (100\%) & Trucks (72\%) & $\begin{array}{l}\text { Rail, ship, } \\
\text { pipeline (28\%) }\end{array}$ \\
\hline $\begin{array}{l}\text { External } \\
\text { climate cost }\end{array}$ & 0.8 & 2.1 (bus) & 0.5 & $\begin{array}{l}\text { Air } \\
0.4 € c t / p k m \\
\text { Rail } \\
0.1 € c t / p k m\end{array}$ & 1.5 & 1.1 & \\
\hline $\begin{array}{l}\text { External air } \\
\text { pollution and } \\
\text { noise cost }\end{array}$ & 4.3 & 21.4 (bus) & 0.1 & & 37.9 & 2.0 & \\
\hline $\begin{array}{l}\text { External } \\
\text { accident cost }\end{array}$ & 0.3 & & $0.1-0.2$ & & 1.1 & $0.8-1.2$ & \\
\hline $\begin{array}{l}\text { External } \\
\text { marginal } \\
\text { congestion } \\
\text { cost }\end{array}$ & $0.6-242.6$ & $\begin{array}{l}1,2-576.3 \\
\text { (bus) }\end{array}$ & $0-139.2$ & & $0-703.5$ & $0-403.8$ & \\
\hline $\begin{array}{l}\text { Wear and tear } \\
\text { infrastr. cost }\end{array}$ & 0.8 & 2.7 (bus) & 0.2 & $\begin{array}{ll}0.2 & € \mathrm{ct} / \mathrm{tkm} \\
\text { (rail) } & \end{array}$ & $0-7.9$ & $0-105.0$ & $\begin{array}{ll}0.2 & € \mathrm{ct} / \mathrm{tkm} \\
\text { (rail) } & \end{array}$ \\
\hline $\begin{array}{l}\text { Oil } \\
\text { dependency }\end{array}$ & $\mathrm{x}$ & & $\mathrm{x}$ & Air & $\mathrm{x}$ & $\mathrm{x}$ & \\
\hline $\begin{array}{l}\text { Economies of } \\
\text { density }\end{array}$ & & $\mathrm{x}$ & & $\mathrm{X}$ & & & \\
\hline
\end{tabular}

Table 1. Relative importance of different modes and external cost estimates (All values are taken from the EU Handbook of External Cost (2014), except for climate damage; here a value of 25 Euro/ton was used - and there is a strong variation for all estimates).

The figures reported in Table 1 imply a wide range of estimated external costs of transport in Europe. For passenger transport, we distinguish urban and medium plus long distance transport. In urban areas, the most important marginal external cost of car use is congestion, followed by climate change, other environmental externalities, and accident risks. Apart from the car, the main alternative urban transport modes are public rail and bus service. The major external cost of urban public transport is crowding among public transport users. ${ }^{4}$

\footnotetext{
${ }^{3}$ All data are based on the Statistical Handbook of the EU for 2014.

${ }^{4}$ This is not represented in Table 1
} 
For medium to long distance transport, the externalities of car use are less important than in urban areas, as there is less population exposure to air pollution and less road congestion. The most important externalities are still congestion and climate change. As before, rail and bus are the main alternatives to car use. But for medium and long distance transport, it is well known that bus and rail service faces economies of density problems. Whenever demand is low, the low frequency that is offered makes the public transport modes unattractive. Additional users allows frequency to be increased, implying an external benefit for all existing users due to a smaller average waiting time at stops or more convenient service. Apart from yielding economies of density, additional users also allow public transport companies to benefit from economies of scale, lowering average costs per passenger kilometer. Finally, for long distance travel, high speed rail (HSR) and air transport are the most important alternatives to the car. In the EU, rail is mostly offered by the public sector, while air transport is privately offered. In terms of externalities, per passenger kilometer air is more carbon intensive than rail.

Turning to freight transport, for short distances there is hardly an alternative for road transport. For medium to long distance freight movements, and depending on local circumstances, rail and inland waterways are the main alternatives. Both are slower, but they cause less external costs per ton kilometer.

One of the main recent issues in EU transport policy is the large oil dependency of car transportation-oil use accounts for 90 percent of fuel used by cars. In the EU (White Paper, 2013) this is considered to be problematic for two reasons. First, there is an important import bill. Second, the sector becomes highly vulnerable to oil supply shocks. However, for economists who believe in the benefits of trade based on comparative advantage, a large import bill is not really an issue. The EU is already among those federations with the highest consumption taxes for oil products, and these can be seen as import taxes that alter the terms of trade. The import bill argument is therefore open to question. Furthermore, the oil shock and unreliability argument is also not an entirely convincing basis for decreasing oil dependency. Note that since 1973 the EU has not experienced a real rationing of oil supply (Kilian, 2008); in fact, price shocks were often generated by demand rather than supply shocks. Emergency stocks and growing non-OPEC supply (non-conventional oil from North America) further limit the risks of politically motivated supply interruptions. ${ }^{5}$

\subsection{Policy objectives and policy instruments}

The choice of policy instruments at the European level has to be seen historically as a gradual reform process, starting from purely national policy priorities, and ideally converging to an EU-wide optimum. The EU has defined

\footnotetext{
${ }^{5}$ For example, for the United States Brown and Huntington (2010) suggest that the costs (not taken into account by the private sector) arising from the vulnerability of the macro-economy to oil price volatility are not especially large.
} 
policy objectives and preferred policies in a series of Green and White Papers ${ }^{6}$. Over the past 20 years there has been a strong re-orientation of the objectives formulated. In the 1992 White Paper, the main focus was still on integrating the EU-economies by lowering transport costs and liberalizing the trucking industry. In 1995, a new focus came into play: next to regulation, transport pricing was suddenly considered as an important additional instrument. Transport taxes could be used not only to generate tax revenues but also to stimulate transport users to make better decisions regarding transport mode, the type of vehicle used, and when and where to make trips. Evidence was presented that "there is a significant mismatch between prices paid by individual transport users and the costs they cause - both in structure and in level" (Com(95)691 p i). For the first time, there was reference to the external costs of car and truck use, including congestion as an external cost, and there were references to solutions like road tolls in congested areas, differentiated fuel taxes to reflect differences in air emission rates between gasoline and diesel vehicles, etc.. That getting the prices right was now stated as an explicit priority was de facto a revolution in the transport community, and the following White Papers turned the clock somewhat backwards. For example, the 2001 White Paper again put more emphasis on quantitative objectives (such as a specific minimum share of public transport) and on the financing of new infrastructure.

From 2011 onwards, the reduction of carbon emissions and oil dependency and the promotion of renewables became additional focuses of EU transport policy. In the most recent white paper (Com(2013)17final), a European alternative fuel strategy (biofuels, electric vehicles) is presented. The main justifications for this strategy are oil import dependency, the deficit in the EU-trade balance (up to 2,5\% of GDP), and the oil price hikes. These were "driven by speculation" according to the EU document and were estimated to cost 50 billion US dollar per year in additional import costs (Com(2013)17final). The idea was that the promotion of alternative fuels would boost growth in Europe. Moreover, they were considered necessary to reach the official EU wide objective of a $60 \%$ reduction of carbon emissions in 2050 (compared to 1990), and they would help to reach the air quality objectives.

Summarizing the main policy lines (see the 2011 and 2013 White Paper), we now have three main objectives

- Resource efficiency (less carbon intensity, less oil dependency, electro-mobility).

- A strong emphasis on promoting public transport for passengers (rail and bus in urban areas, and high speed rail for longer distances), and promoting rail and inland waterways for freight.

- A European multimodal transport information, management and payment system.

These policy objectives are often translated into quantity or market share objectives such as " $50 \%$ of urban mobility should be carbon free in 2030". Operationalization of the objectives is often achieved using regulations

\footnotetext{
${ }^{6}$ Different White papers were published: the 1992 White paper (market opening), the 2001 White Paper ("European transport policy for 2010: time to decide"), the 2006 White Paper ("Keep Europe moving: a transport policy for sustainable mobility"), the 2011 White paper ("Roadmap to a Single European Transport Area. Towards a Competitive and Resource Efficient Transport System"), and the 2013 White paper ("clean power for Transport: a European alternative fuels strategy").
} 
and infrastructure subsidies at both the EU (for example, car emission standards) and member state levels (for example, subsidies for electric car refueling infrastructure).

Table 2 presents the main instruments used for taxing and regulating road transport. The most important instruments currently used are still fuel taxes on cars (gasoline and diesel) and on trucks (diesel). For cars and light vans, fuel taxes are complemented by EU fuel efficiency standards imposed on deliveries of car manufacturers to EU customers and by lower member state taxes, or even subsidies, for other fuels (biofuels, natural gas, electricity). The fuel efficiency standards apply to the weighted average of new cars put on the market by each manufacturer. Despite the high subsidies, the share of other fuels is still very low: biofuels are blended with conventional motor fuels and their fuel share is less than $5 \%$. The number of electric vehicles and natural gas vehicles makes up less than $1 \%$ of the new vehicle fleet. Returning to Table 2 , most countries also tax vehicle purchases and ownership, but the tax formulas differ widely among countries. Moreover, in almost all urban areas parking charges are used as an instrument to ration parking demand by non-locals and locals. Parking charges have progressively replaced permits, parking time restrictions and other regulations. They are currently not used to curb congestion, although they could be. Moreover, work-related parking is often subsidized. Finally, only a few cities (London, Stockholm, Milan) have implemented some limited form of road pricing in function of place and/or time of use. Motorway tolls have been used to finance motorway construction in some countries (historically France, Spain, Italy $^{7}$ ).

In those countries where there are no infrastructure tolls, taxes on truck trucks are complemented more and more by additional infrastructure payments in the form of daily or yearly passes (vignettes) that are unrelated to distance, or by charges related to distance. The infrastructure charges are also a function of the infrastructure damage (by differentiation according to axle weight) and environmental parameters of trucks. In addition, all fuel purchases (including excises) for trucks and cars are subject to VAT; however, firms will not pay the VAT, as fuel is an intermediate input ${ }^{8}$.

Quantitative policy objectives have the advantage of being easy to monitor, but they also have important disadvantages. First, the cost and benefits of reaching the objective are uncertain. Since Weitzman (1974), economists prefer price instruments, as they can better deal with uncertainty over future (e.g., energy and technology) costs. This is even more so when the EU-objectives are implemented country by country, where the costs of meeting these objectives can vary considerably across countries.

\footnotetext{
${ }^{7}$ Large toll roads are these days also found in Portugal, Slovakia, Slovenia, Poland and Austria (ITF, 2013).

${ }^{8}$ VAT-rates are not applied to all modes of transport. In several EU countries, there is no VAT on aviation, rail or public bus services.
} 


\begin{tabular}{|c|c|c|}
\hline POLICY INSTRUMENT & CARS & TRUCKS \\
\hline Gasoline excise & Yes & \\
\hline Diesel excise & \multicolumn{2}{|c|}{ Yes } \\
\hline Tax \& subsidies for other fuels & $\begin{array}{l}\text { Lower tax (LPG) or subsidy } \\
\text { (electricity) }\end{array}$ & \\
\hline $\begin{array}{l}\text { Vehicle purchase and ownership } \\
\text { taxes }\end{array}$ & $\begin{array}{l}\text { In function of value, sometimes in } \\
\text { function of } \mathrm{CO} 2 \text { emissions and often } \\
\text { with a surcharge on diesel cars }\end{array}$ & $\begin{array}{l}\text { Eurovignette is fixed sum per year } \\
\text { that is function of axle weight and } \\
\text { Euro norm }\end{array}$ \\
\hline Parking charges & In most cities & \\
\hline Distance charging & No & $\begin{array}{c}\text { Germany, Austria, Poland, Slovenia, } \\
\qquad . . .\end{array}$ \\
\hline Toll roads & \multicolumn{2}{|c|}{ France, Italy, Spain , Portugal } \\
\hline $\begin{array}{l}\text { Road pricing by time of day and by } \\
\text { place }\end{array}$ & London, Stockholm, Milan, Goteborg & No \\
\hline Fuel efficiency regulations & yes & small vans only \\
\hline Conventional emission regulations & yes & Yes \\
\hline
\end{tabular}

Table 2. Main instruments used for taxing and regulating road transport

Of course, in terms of policy instruments, the EU is limited to its domains of competence: climate policy, international transport and competition policies (vehicle and fuel standards, markets for public transport). Urban and regional policy issues like congestion and local public transport do not fall within EU competence.

National and EU decision processes differ. National decision processes vary across member countries and usually involve a majority in Parliament; often, they also require a qualified majority over regions. These processes can be slow, but they seem to work. At the EU-level the procedure is more complex. First, for tax measures unanimity is required, while other measures require a qualified majority only. Second, initiatives are usually taken by the Commission, but they need to pass a double hurdle: the Council of Ministers and approval by the European Parliament. Finally, most regulations need to be implemented by the member states. Therefore, the process is lengthy and can be difficult. A famous example is the "Eurovignette" directive that regulates the charging of trucks. The initial proposal was made by the Commission in 1999, based on a Green paper of 1995. There was a demand by the European Parliament and the Council to have a better and more generic directive in 2006, and the new Eurovignette directive was only voted in 2011 (Weismann, 2013). It is therefore no surprise that many member countries took national initiatives to implement new charges for trucks before the final directive was voted upon.

\section{Evaluation of pricing and regulation policies for passenger transport}

We start this section with an appraisal of the current instruments used toward car transport. Then we look into the possibilities of using new pricing instruments for controlling car use. Finally, we briefly discuss policies that might 
complement the use of novel car pricing instruments. Specifically, we focus on pricing and supply of public transport, and we point at the relation between transport and labor market policies.

\subsection{Successes and failures of the current instruments used for car transport}

For car transport, most countries rely primarily on a combination of fuel taxes, vehicle purchase or ownership taxes and regulatory measures to achieve two main objectives: addressing external costs of car use, and raising tax revenues in an equitable way. Intra-country and international cross-border shopping limits the spatial variation of the gasoline and diesel tax. Moreover, this tax does not differentiate in terms of time of use. Hence, these instruments are poorly suited to addressing some of the external costs, especially congestion. But of course, there are many more ways to control externalities, and other policy instruments apart from fuel taxes could help. The most commonly used other instruments to control externalities are tax policies towards alternative fuels, purchase and ownership taxes on vehicles, and standards on vehicles (air pollution standards, fuel efficiency standards -- or equivalently $\mathrm{CO}_{2}$ emission rates -- and safety standards).

In what follows, we consecutively deal with the gasoline tax, the taxation of fuels that substitute for gasoline (diesel, ..), taxes on vehicle purchases or annual ownership taxes, the regulation of car emission policies, and specific policies to stimulate the purchase of alternative fuel and electric vehicles. We do not discuss some other types of regulations such as specific safety regulations for road use (for example drunk driver penalties, speed regulations,...).

\section{The gasoline tax}

If countries use the gasoline tax as the main instrument to address all externalities of car use, the tax should be in line with the following expression, to which one can add a margin for revenue raising: ${ }^{9}$

Fuel tax/liter $=$ carbon damage/liter

$+\gamma$ (marginal external congestion, accidents, air pollution costs per veh $\mathrm{km})(\mathrm{km} / \mathrm{liter})$

In this expression, $\gamma$ is the fraction of the fuel reduction from reduced vehicle use in response to the tax. As just mentioned, the externality component can be augmented by an additional margin to capture the revenue raising function of the tax.

To understand the above expression, first note that the most straightforward element is the carbon damage, because there is a proportional relationship between carbon emissions and fuel use. We know carbon damage per ton should in principle be uniform over all sectors of the economy; based on recent estimates, in the EU it could be of the order of 20-25 Euro/ton of $\mathrm{CO} 2$ (this boils down to 0,06 euro per liter for gasoline and 0.07 euro per liter for diesel). Second, internalizing other externalities with a fuel tax requires a correction factor $\gamma(\gamma<1)$ that takes into account the share of fuel reduction that is due to reduced driving rather than to more fuel efficient cars. As

\footnotetext{
${ }^{9}$ See Parry et al. (2014) for details and an application to many countries in the world.
} 
other externalities are related to distance rather than to fuel use, this component of the fuel tax wants to stimulate reduced driving rather than improvements in average fleet fuel efficiency. What complicates matters is that, whereas climate damage is independent of the location of the carbon emissions, the external cost of other externalities depends on location: accident externalities, congestion and air pollution all vary by time and place.

Of course, a further complication is that there are many other ways to reduce such other externalities than through a reduction in total mileage: vehicles can be cleaner, safer, drivers can be more cautious, they can drive at other times and/or take other routes. Although the EU handbook on external costs is an important step forward there is, therefore, an obvious need to sharpen the external cost estimates, and to show how to apply them in more precise optimal tax formulas. There are two particular priorities. First, we need to know better what is the level of marginal congestion costs and how it reacts to vehicle volume in a network. Second, we need to have a better understanding of the conventional air pollution externalities, and we need to know what are the main differences between gasoline and diesel cars.

\section{Taxation of fuels that substitute for gasoline}

Before turning to the use of other instruments, it is instructive to study the taxation of fuels that substitute for gasoline. The most important substitutes are diesel, LNG, CNG, biofuels and electricity. There is no reason to apply a different taxation principle to substitutes of gasoline than to gasoline itself. Europe has a strong penetration of diesel cars, and this evolution is a matter of intensive debate. When we apply the same tax principle as above to diesel cars, there is clearly a need for a higher tax per liter on diesel than on gasoline. Although, of course, diesel and gasoline cars produce the same mileage-related externalities, there are two reasons for this. First, the carbon emission per car-kilometer is slightly lower, but other air pollution damage is higher for diesel than for gasoline; the net effect implies slightly higher external costs per kilometer for diesel. Second, the main reason why the diesel tax per liter should be higher is that a diesel car drives some $20 \%$ more kilometers with a liter of fuel than a gasoline car. Hence, to internalize the same mileage-related externalities, one needs a higher tax per liter on diesel Despite these simple principles, many EU-countries continue to tax diesel fuel at a lower rate than gasoline, where diesel advantage can be up to 50 cent/liter compared to gasoline. Of course, diesel is also used by trucks so that diesel taxes are a compromise between car and truck use. In the case of cars, one can easily bring in other specific tax instruments for diesel cars (purchase or registration taxes) to correct for too low diesel fuel taxes ${ }^{10}$. But these are much less efficient second best taxes, as diesel fuel use by cars will still not be sufficiently taxed. Not surprisingly, the tax treatment of diesel implies that diesel cars have a large market share in many European countries (see Figure 1).

${ }^{10}$ Countries often 'compensate' the lower diesel tax by imposing higher annual vehicle and ownership taxes on diesel car owners. For a formal numerical simulation model analyzing the optimal taxation of diesel and gasoline car ownership and car use, see De Borger and Mayeres (2007). 
Finally, the same tax principle given above also holds for biofuels and electricity. However, for these fuels one can advance a learning by doing argument to justify a more favorable tax treatment until these vehicles have more substantial fleet penetration.

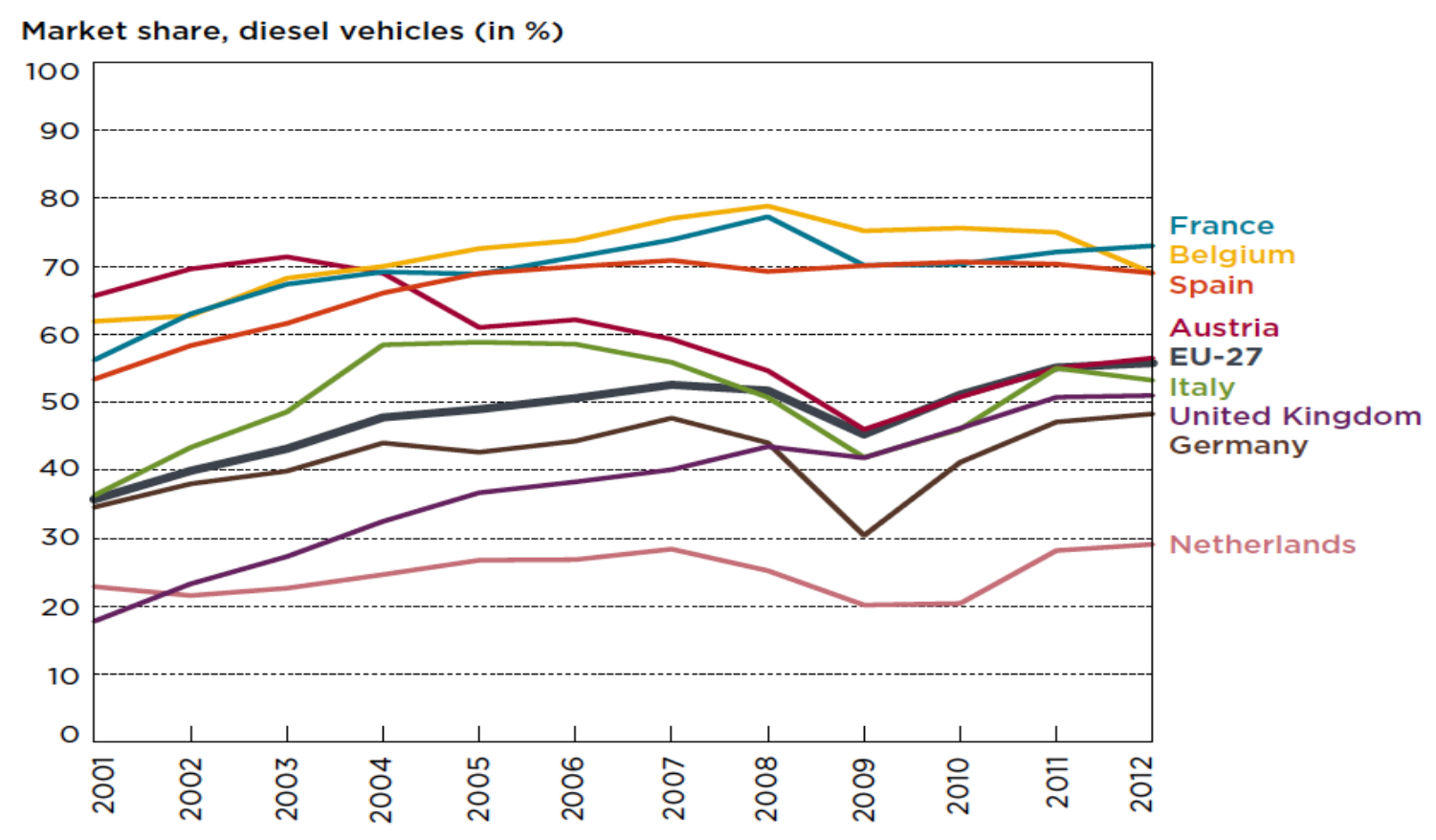

Figure 1. The share of diesel in new car sales in selected countries (2001-2012). Taken from the EU-vehicle market pocket book (ICCT, 2013).

\section{Vehicle purchase and ownership taxes}

Other instruments that have been used intensively are vehicle purchase and ownership taxes. Different member countries have been using these instruments for environmental and tax revenue objectives in widely different ways (for example, registration taxes often depend on $\mathrm{CO} 2$ characteristics, but they do so according to very different formulas). Moreover, there is a large variation in the level of these taxes. For example, although many (but not all) member countries have both a VAT on vehicle purchases, a registration tax and an annual vehicle tax, the level of the registration tax varies between zero and more than a $100 \%$ of the purchase price.

In what follows, we illustrate the variety of car ownership policies by focusing on Denmark and the Netherlandscountries that have a tradition of high ownership taxes to cope with car externalities and that have recently fundamentally reformed their tax system. Both countries favored high purchase and registration tax policies to discourage car ownership, particularly of large cars. For example, in Denmark owners pay up to a $200 \%$ purchase tax on a car. Revenues from non-fuel taxes on cars were equal to $1.5 \%$ and $1.2 \%$ of GDP in Denmark and the Netherlands, respectively, compared with an average of $0.5 \%$ for the EU as a whole. To put this into perspective, 
fuel taxes represent some $1.4 \%$ of GDP, on average ${ }^{11}$. The efficiency and equity effects of these high non-use tax policies have not yet been analyzed very thoroughly. Considering equity, ownership taxes of course tend to discourage car ownership but, even if this tax is progressive in the value of the car, the net equity effects are not obvious. They depend, among others, on how ownership of different car types varies across the income distribution. As for efficiency, there is strong evidence that high purchase taxes on new taxes may induce postponing car replacement, leading to rather old car fleets and high pollution. This was the case in the Netherlands and Denmark, until both countries recently reformed their purchase tax systems. High recurrent taxes on car ownership do not have this disadvantage.

\section{The wrong tax reform in Denmark}

First, consider the tax reform in Denmark; this consisted of moving from the existing system towards a strong feebate system. Munk-Nielsen (2014) documents how the reform, introduced in 2007, gave rise to a strong switch to more fuel efficient vehicles. To illustrate its implications, take as example a fuel efficiency improvement from $6.25 \mathrm{l} / 100 \mathrm{~km}$ to $5,25 \mathrm{l} / 100 \mathrm{~km}$. This gives a feebate of 1560 Euro or, using a mechanical calculation, a subsidy of the order of $1000 \mathrm{Euro} /$ ton of $\mathrm{CO} 2$. Based on a detailed modeling exercise, MunkNielsen derives a more precise estimate of the cost of the system for the Danish car market as a whole, taking into account the rebound effect and the other external costs of driving. He arrives at a subsidy of $1545 \mathrm{Euro} /$ ton of $\mathrm{CO} 2$ saved. This makes the system very inefficient compared to $\mathrm{CO} 2$-saving efforts in other economic sectors (e.g., recent $\mathrm{CO}_{2}$ prices in the EU Emissions Trading System have been below <5??> euros per ton). In addition, the focus on $\mathrm{CO}_{2}$ reduction led to an increase on the share of diesel cars in the new car stock in Denmark from $5 \%$ to $40 \%$. This is difficult to justify, given the higher air pollution damage of diesel cars.

\section{The Netherlands: another costly tax reform}

From Table 1, we know that the external costs of a car are strongly related to car use and not to the ownership of a car, so there is a lot of room for tax reforms that substitute high purchase and ownership taxes by user taxes. The Netherlands has tried to use this opportunity in 2006 to transform the purchase and ownership taxes into road user taxes, a reform that did not go through (also see the next section). Instead, in the period 20062010 the Dutch government changed the structure of the purchase tax from a tax based on the value of the car to a progressive CO2-tax. An example may illustrate the implications. Take the substitution of a $13,3 \mathrm{l} / 100 \mathrm{~km}$ car by a car consuming $10 \mathrm{l} / 100 \mathrm{~km}$. This gives a reduction of the purchase tax of 12500 Euro and, using again a purely mechanical calculation ${ }^{1}$, it implies a saving of 5.2 ton of CO2. This leads to a cost of 2403 Euro/ton of CO2. Of course, for more fuel efficient vehicles the progressive tax will be smaller, but the cost is still of the order of 1000 Euro/ ton of CO2. Moreover, according to van Geilenkirchen et al. (2014), the net saving of CO2 emissions is much smaller than previously indicated due to the rebound effect. Taking this into account, they estimate that the tax reform leads to CO2-savings of only $0.1 \%$ in the short run and $1 \%$ in the long run. The Dutch tax reform did avoid the promotion of diesel cars, but instead it strongly promoted the purchase of hybrid cars: in 2009 , hybrid cars represented $4 \%$ of new car sales in the Netherlands, to be compared with a market share of less than $1 \%$ in the rest of the EU (ICCT, 2013).

\footnotetext{
${ }^{11}$ Taken from the EU-Transport Pocket Book 2013. The data are for 2011; they are labeled as "Environmental taxes as \% of GDP - transport (non fuel)".
} 
Besides Denmark and the Netherlands, several other countries, including France and Germany, have used a scrappage scheme in the period 2008-2010. The net effect on CO2 was low or even negative (D'Haultfoeuille et al., 2013 ) and, if one does not account for the macro-economic stimulus, this program was costly.

In view of the policies implemented in European countries, it comes as no surprise that $\mathrm{CO}_{2}$ emissions declined substantially over the past decades (see Figure 2). However, the above discussion makes clear that this reduction was achieved at a huge economic cost, and that more efficient policies (sticking to fuel taxes or more efforts in non-transport sectors) might have generated the same savings in emissions at much lower cost.

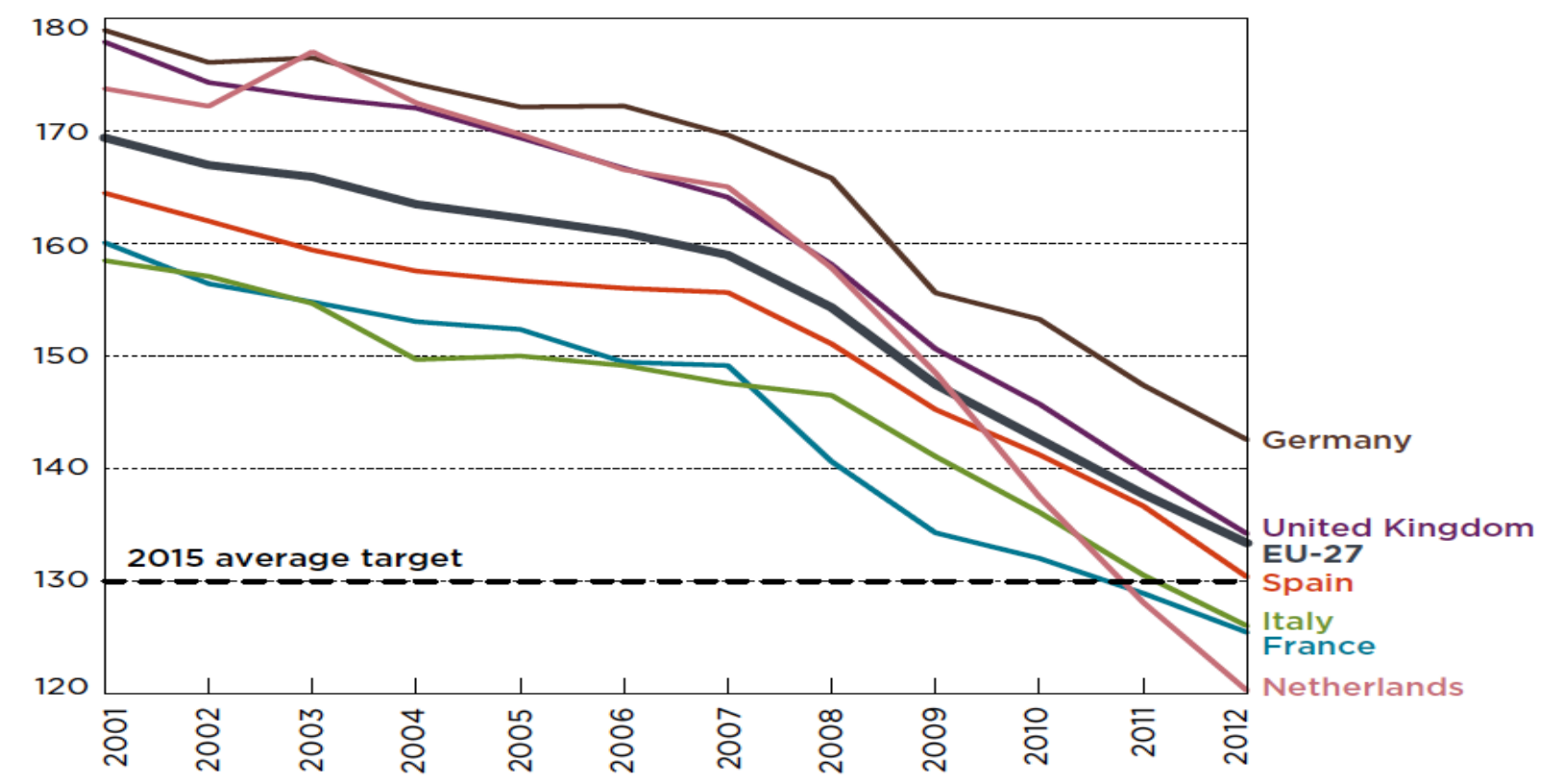

Figure 2. Average CO2 emission (test cycle) for new passenger cars (vertical axis) in several member countries (source IICT (2013))

\section{Regulation of air pollution and carbon emissions}

One of the most effective additional instruments to control the environmental externalities of car use is the regulation of emissions of traditional air pollutants. The Auto-oil program of the EU regulated the emissions of new cars and the quality of fuel. This regulation was efficient to tackle traditional pollutants in the sense that, by installing additional equipment at relatively low cost, emissions could be reduced by a factor 5 to 20 (Calthrop and Proost, 2003). The efficiency of the more recent and more stringent emission standards for traditional air pollution is more controversial, and serious doubts remain on the efficiency of the regulation of air pollution by diesel cars. For example, the NOx standard of 2009 requires a maximum emission of $0.18 \mathrm{~g} / \mathrm{veh} \mathrm{km}$ in the test cycle while the real emissions could be four times higher (ICCT, 2013). With more strict emission limits and increasing marginal 
abatement costs, it pays to fine tune the performance of the car specifically for the test cycle and to leave out of the test the engine load regimes that constitute real-world driving (e.g., uphill driving, acceleration on a ramp, or positive accelerations from a standstill). This results in an ever larger difference between test cycle emissions and the real emissions. On the positive side, emissions rates maintained (at least partially) over vehicle life through periodic inspections programs.

Fuel efficiency regulation for cars to reduce $\mathrm{CO} 2$ emissions is a more costly objective for several reasons. First, there is no technical measure like a catalytic converter or the use of fuels with a lower sulfur content that can reduce carbon emissions by a factor 5 to 20, as was the case for traditional air pollutants. Second, there is already an important carbon tax; it is called a gasoline tax. The gasoline tax (amounting to some 200 Euro/Ton of CO2) is much higher than the carbon tax or the carbon abatement cost in other sectors of the economy (note that the price of tradable emission permits for $\mathrm{CO} 2$ varied between 5 and 30 Euro/ton of CO2). The simple reason is that the gasoline tax also serves to raise revenues and to internalize other externalities. For these reasons, too much fuel and CO2 saving is undesirable. We are already pushing very hard on CO2 reductions through high fuel taxes and (to varying degrees) vehicle taxes related to CO2 emissions - so additional incentives on top of these through $\mathrm{CO} 2$ per km regulations likely very costly.

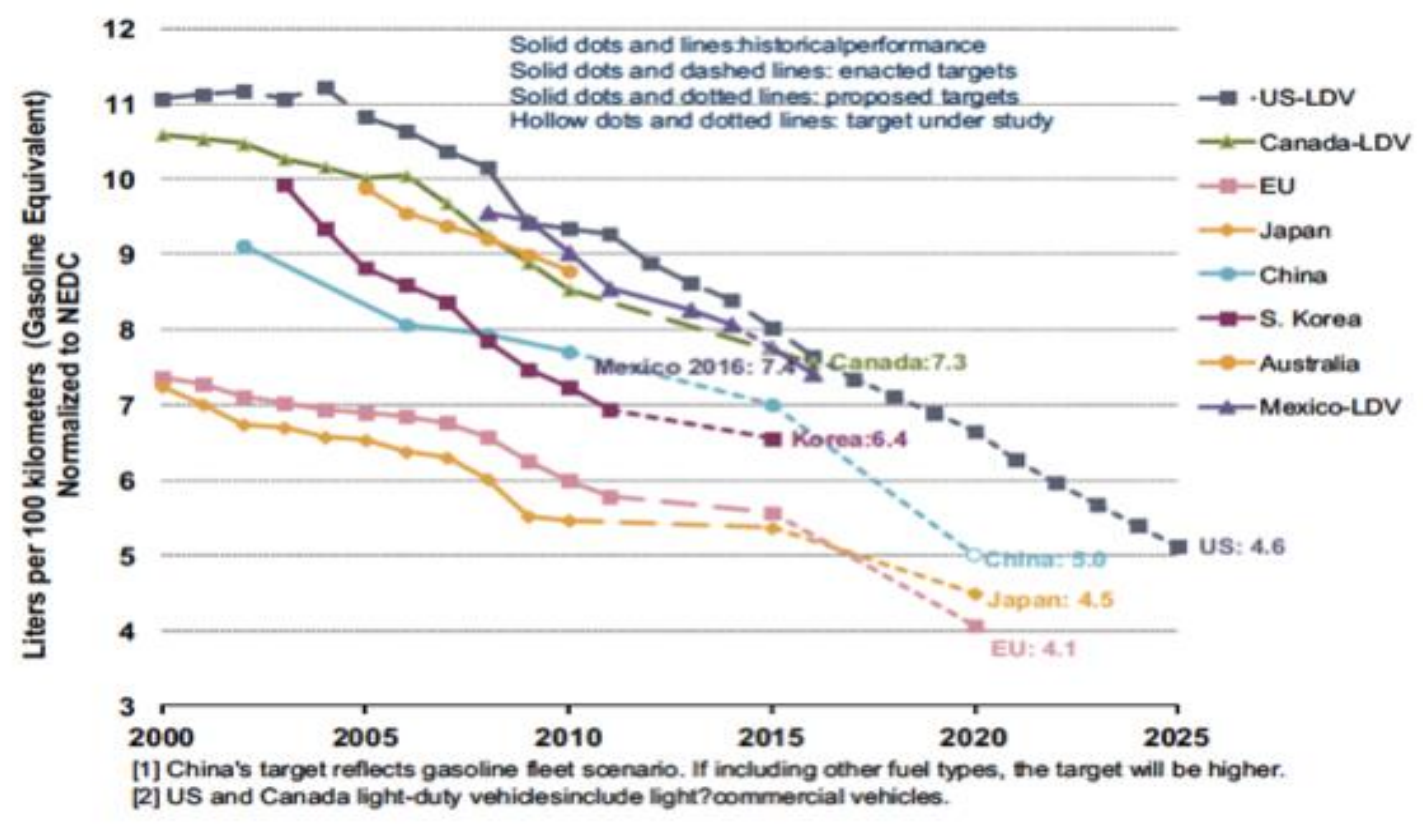

Figure 3 : Fuel economy performance, and planned and prospective fuel economy standards, selected countries (Source: ICCT, 2011)

The standard case in favor of a fuel efficiency standard to reduce $\mathrm{CO} 2$ emissions is twofold. One argument often invoked by the EU is that of myopic consumers. However, the evidence to support the argument is mixed at best . For example, Grigolon, Reynaert and Verboven (2014) show that, when EU consumers make car purchase 
decisions, they take into account close to $90 \%$ of the effect of fuel prices. Moreover, even if they would be myopic, jointly considering myopia and externalities imply that fuel efficiency standards could still be outperformed by fuel taxes (Parry, Evans and Oates, 2014).

A second argument in favor of efficiency standards is that they require, for the same total CO2-savings, more technological progress than a tax instrument; this technology element spills over to the rest of the world (Barla and Proost, 2012, Dechezlepretre and Popp, 2014). The latter argument would be in line with the EU's voluntary climate policy: the EU is indeed a world leader in terms of fuel efficiency (see Figure 3). But if we want to have a successful transfer of technology, we may need to re-orient our technology standards towards less ambitious targets, as other countries have a less ambitious climate objective and do not want to pay for fancy super-efficient technologies (Eliasson and Proost, 2014). Finally, does the world really benefit from the EU's efforts to make diesel cars much more fuel efficient?

\section{Alternative fuels and electric vehicles}

As part of the EU climate and energy policy, there was a directive pushing for the use of biofuels (bio-ethanol and bio-diesel made from biomass) and the promotion of electro-mobility. The most successful country in introducing biofuel cars was Sweden, where a subsidy program increased the market share (in new car sales) of flexible fuel cars from $8 \%$ in 2006 to $22 \%$ in 2008 (ICCT, 2008). Huse (2014) analysed the Swedish Green Car Rebate in great detail. This program gave a subsidy of 1300 to 1500 Euro for the purchase of a medium size flexible fuel car, a car that could run on gasoline and on biofuel (ethanol) or other less $\mathrm{CO} 2$ intensive fuels ${ }^{12}$. In addition, the program was more lenient for the fuel efficiency of flexible fuel cars. As it is easy and cheap to turn a standard car into a flexible fuel car, the consequence was that suppliers offered very quickly flexible fuel car variants, but in a less fuel efficient version ${ }^{13}$. Consumers could arbitrage between gasoline and biofuels and, when oil prices dropped, ended up using a lot of gasoline. The final result was an expensive subsidy program, achieving a high share of flexible fuel cars, but with a low environmental effectiveness. Similarly, it would be no surprise that the current stimulus for electro-mobility is, with present technologies, also not a very cost-effective option to reduce carbon emissions (see Christ, 2012).

It is useful to turn to the implications of fuel efficiency standards and subsidy programs for more fuel efficient cars for the manufacturers. As they are bound by an average standard on the sales of new cars in Europe, any incentive by one country to impose more fuel efficient cars implies that a manufacturer can afford to sell less fuel efficient cars in other countries. Two other particularities of the fuel standard are worth mentioning. The first is that the average fuel efficiency does not take into account the expected mileage; this gives a too large weight to electric

\footnotetext{
${ }^{12}$ Huse (2014) reports an emission reduction of $45 \%$ when gasoline is replaced by ethanol from sugarcane production. Of course, there are many other environmental issues associated to the production and use of biofuels than $\mathrm{CO} 2$ emissions; these are not discussed here.

${ }^{13}$ This happened to be often large, home-produced Volvo's.
} 
vehicles, as these are typically used for short trips. The second issue is that there is a widening gap between the theoretical measurement of fuel consumption defined in the standard and effective fuel consumption. The ICCT (2013) reports an additional real world consumption of fuel that was of the order of $7 \%$ in 2001 , but it has increased to $20 \%-25 \%$ in 2011 , the reason is again the fine tuning of performance for a specific test cycle. . So the way the current standard is formulated is less and less realistic.

\section{Summing up}

Summarizing, the main instruments used by the EU to tackle externalities are high fuel taxes and fuel efficiency standards; here it has been a forerunner compared to other parts of the world. High fuel taxes have been a second best instrument to correct several externalities at the same time. The stringent fuel efficiency standard has been eroding the effectiveness of the high fuel tax. Some member states, overestimating the benefits of gasoline savings, have launched very costly subsidy programs for even more fuel efficiency, or to promote the use of alternative fuels. Promotion of alternative fuel vehicles may benefit from technical compatibility standards (as argued by Vollebergh and van der Werf (2014)), because these allow network effects and reduce costs. But the EU has imposed costly minimum market shares and is lagging behind in agreeing on technical compatibility standards.

\subsection{Acceptability of new instruments for pricing cars.}

We discuss consecutively urban congestion pricing, low emission zones, parking and paying for motorway use.

\section{Urban congestion pricing}

For a long time, all big cities tried 'standard' instruments, such as offering cheap and extensive public transport services and charging high prices for parking, in their effort to reduce externalities. These instruments did have some effects, but they failed to solve congestion problems; moreover, they were expensive ${ }^{14}$. Singapore was the first city to implement some form of congestion pricing. Now many cities in the EU are potentially interested in new price instruments to curb congestion, but very few also implement them. Cities that did introduce new pricing instruments include London (2003), Stockholm (2007) and Milan (2012); Goteborg introduced it in 2014 but the system was voted down later ${ }^{15}$. London has implemented zonal pricing; Stockholm and Milan implemented cordon tolls with prices varying by the time of day. In a cordon pricing system, road users pay only when entering the

\footnotetext{
${ }^{14}$ A few papers made a systematic (but very simplified) comparison of the relative welfare gain of different instruments to address externalities in a city. Proost and Van Dender (2001) find that public transport optimization as the only instrument can achieve only some $30 \%$ of the maximum welfare gains that could achieved by a combination of pricing of cars and public transport. Basso and Silva (2014) find similar results for London; for Santiago de Chile, where busses are the dominant transport mode, they find, not surprisingly, that a policy focusing on reserved bus lanes is as good as road pricing. For non-urban transport, De Borger and Mayeres (2007) illustrate the huge welfare loss of using pricing instruments that are not time-differentiated.

${ }^{15}$ The Goteborg toll was not accepted by the public in a referendum. It was nevertheless accepted by the local parliament, mainly because it allowed to benefit from national investment funds that match the toll revenues.
} 
zone, but trips within the zone are free. In zonal pricing systems, one also pays for trips within a given zone. Many more cities were tempted and quite a few organized referenda about the issue, but they never implemented the new instrument. Although the EU seems to be the world leader in the implementation of some form of road pricing, the question remains why only a few cities took the final step. This may seem surprising, because careful analysis of the experience in the different cities shows that the implementation of these road pricing measures have been welfare improving, provided that the revenue has been used productively (see Anas and Lindsey (2012)).

Several lessons can be drawn from the available experience. First, the design of road pricing systems is very important for the net welfare effect. For example, Stockholm was more efficient than London, because the system had lower transaction costsand more finely differentiated charges ${ }^{16}$. Second, a striking feature is that only a small share $(25 \%)$ of the suppressed car trips switched to public transport; the rest of the trips disappeared due to more car sharing, combining trips, or simply foregoing the trip. A third conclusion from the analysis of the experience in London (Transport for London) and in Stockholm (Eliasson et al. (2009)) is that more people were in favor of the road pricing system after it was introduced (ex post) than before its implementation (ex ante).

\section{The political economy of road pricing}

De Borger and Proost (2012) analyze the political economy of road pricing, using a model of policy reform. Road users have an initial majority, but they are uncertain about the individual costs of switching from car use to public transport, or to foregoing the trip altogether. They show that this uncertainty implies a high expected substitution cost, and that it is likely to lead to a negative expected benefit for initial car drivers. Assuming that non-drivers also share in the collected toll revenues, car drivers perceive high expected substitution costs and low revenue from toll charges before introduction of road pricing, because they have to share toll revenues with non-drivers. After implementation, uncertainty is resolved and the decisive car user (being close to the median) will see lower substitution costs, and may vote in favor ex post. The results is that a majority may vote against road pricing ex ante, although a majority would have been in favor after its introduction. The analysis further shows that fewer voters are against road pricing when toll revenues are used to subsidize public transport than when they are redistributed to all voters. Moreover, if the total number of peak trips is price inelastic, one way to limit the toll level and still obtain the same total welfare gain is to subsidize public transport, as it is mainly the net price difference between road use and public transport that drives the modal shift. In addition, this strategy prevents that revenues are shared with those that do not travel. The results of the paper are consistent with a number of recent empirical observations on efforts to introduce road pricing, including the systematic rejection of road pricing in referenda, the more favorable attitudes towards road pricing after than before its introduction, and tying the toll revenues to support public transport.

\footnotetext{
${ }^{16}$ Transaction costs consist of the pure administration costs of a payment scheme (ranging from 10 to $50 \%$ of total revenues) and of the effort and time costs for users that are associated to the payment. The administration costs of a payment scheme consist for an important part of enforcement costs (identifying number plates of cars, checking whether they paid or not, sending invoices...). There may be an important learning effect here.
} 
In sum, there have been several successful road pricing experiences in EU-cities over the last 10 years. It is expected that more will follow soon, and that this will be an important policy development for the next decade. There are two important questions for this development, besides toll rates and time differentiation. First, what is the best form this road pricing should take: cordon pricing around the city or zonal pricing? This will depend on the geography of the city and the distribution of trips. Second, is the introduction of new instruments best organized as a bottom-up or as a top-down process? Top-down initiatives ("national road pricing") at the level of the federal government were discussed in the Netherlands and in the UK, but they were not accepted. The top-down schemes can avoid that one region exploits its local monopoly power by overcharging trips by non-residents. However, the disadvantage of top-down schemes is their lack of flexibility to adapt to changes in local circumstances. Moreover, acceptability is more difficult because federally imposed differentiated pricing runs the risk of regional discrimination ${ }^{17}$. The schemes that were implemented (London, Stockholm, Milan) are all bottom-up. The risk of monopoly pricing in local schemes can be overcome by constraining the use of the revenues ${ }^{18} 19$. Of course one could also construct a dual system involving elements of congestion charging by both national and sub-national governments (note that the present combination of fuel taxes and parking charges is also a dual system).

\section{Low Emission Zones}

Closely related to road pricing is the proliferation of Low Emission Zones in Europe. The EU directive makes cities and regions responsible for implementing sufficient measures to reach the urban air quality guidelines. A large number of cities (for example, more than 40 in Germany alone, as well as Milan) took this air quality directive seriously (although enforcement is weak or non-existing) and implemented a variety of measures to comply with the objectives. These measures consisted in either banning the most polluting cars or enhancing public transport supply. According to Perry and Wolff (2011), the banning of polluting cars was effective and welfare-improving, while the extension of public transport supply was not. De Borger and Proost (2013) have studied low emission zones and various other externality-reducing measures in an urban environment (for example, traffic lights, speed bumps, bypass roads, etc.). They show how the initiatives taken by cities can very well lead to inefficient policies: too many traffic lights and speed bumps will be placed, and insufficient investment in ring-roads are good examples of poor local policies.

\section{Parking}

Cities have long been using parking charges. High parking charges can be a second best measure to curb excessive car use in cities. Economists have been slow in picking up this instrument, but it has its function. Contrary to road

\footnotetext{
${ }^{17}$ In the Netherlands, there was a political majority for transforming the high fixed car charges into smarter user charges, but one of the reasons the majority broke down is the regional differentiation of the charges.

${ }^{18}$ In London, the revenues served mainly to finance public transport. In Stockholm, the toll revenues are used for additional road infrastructure in the region. In Goteborg, the toll revenues are used for a new rail tunnel under the city.

${ }^{19}$ See De Borger and Proost (2013) for a theoretical comparison of the two schemes and an analysis of the constraints on federal and local schemes that can improve the outcome.
} 
pricing, this instrument is widely accepted. New technological developments and better modelling can increase its efficiency. Of course, efficient parking pricing has to be place and time dependent. The technology to implement such systems is available. For example, in part of San Francisco there is electronic monitoring of parking occupancy, and prices are adjusted regularly to achieve a given occupancy rate (say $90 \%)$.

\section{Paying for motorway use}

Several countries have installed tolling systems to pay for their motorway infrastructure. The tolls have been used mainly to generate revenues, but some motorways start to implement time- and place-dependent tolls. Those countries that have not yet implemented tolling systems on their motorways are now tempted to also charge foreign cars by using vignettes. Switzerland was the first to do so, and other countries will follow; for example, Germany plans introducing a vignette per day, month or year in 2016. These vignette systems can be differentiated by type of car (as in the clean car zones in Germany), but they are not differentiated by distance, by time and by place of driving. The main function of these vignettes is therefore to make foreign users pay for the local infrastructure, because domestic car owners are often compensated by an equivalent reduction of local car taxes. Of course, such vignettes are relatively poor instruments to tackle congestion.

\section{Summing up}

In the longer term, we need higher transport prices in congested urban areas, and possible lower prices in rural areas. This means that the function of gasoline taxes, managed by central government, will be eroded slowly by higher congestion charges and by parking charges that will most likely be set by local governments. The implications of this ongoing evolution for tax levels, environment, infrastructure funding and intergovernmental transfers are still to be studied.

\subsection{Complementary public transport policies}

In dense EU metropolitan areas, public transport has a high market share that can be well over $50 \%$ of passengerkilometers. But in many cities this comes at a high cost, as cost recovery is low (often below $50 \%$ of the operation costs). Parry and Small (2009) find that high operating subsidies for public transport in large cities (they studied London, Los Angeles, and Washington DC) can be justified on the basis of second-best arguments. Subsidies allow exploitation of scale economies due to increased frequency (which reduces waiting times at stops), higher route density (reducing average user cost of accessing the system) and increased load factors (reducing average operating cost). But the most important justification for the high subsidy is that $50 \%$ of the extra public transit trips attracted by the higher subsidy reflects trips that would have otherwise been made by car. In practice, however, many cities have implemented high public transport subsidies but, unfortunately, only a small share of the extra demand came from former car users ${ }^{20}$. The result has been an important congestion problem in public ${ }^{20}$ There is good evidence for Stockholm where the cross-price elasticity for bus is rather low, about 0.1
(M.Borjesson, Fung, Proost, 2015). Van Goeverden et al. (2006) report results on the introduction of free busses 
transport in some cities. With a cost recovery of less than $50 \%$, funding additional capacity is difficult. In addition, most cities do not yet differentiate their public transport fares in function of time of day and place in the network. Even without implementing road pricing for cars, it seems that many cities could benefit from an increase of public transport fares in the peak period (for an illustration for Paris, see Kilani, Proost and Van der Loo, 2014).

Public transport can not only be made more attractive by lower prices, but also by improved quality. This requires investments in trams, metros and high speed rail (HSR). Some countries do have a tradition of high quality public assessment (including the UK, Sweden, the Netherlands and France), but in many other countries such investments have not been assessed by a traditional Cost Benefit Analysis (CBA). It turns out that many large transport projects are not justified according to traditional CBA-methods. For urban transport, there seems to be a systematic preference for expensive trams, which is quite likely unjustified (see Tirachini, Hensher and Jara-Diaz, 2010). For medium to long distance transport, some high speed rail projects are difficult to justify. Several of the projects on the Trans European Network priority list that were eligible for additional EU-funding also have a poor social rate of return (Proost et al., 2013). This illustrates the importance of detailed ex ante evaluation of large-scale investment projects. In this respect, it is encouraging to note that there has been recent progress in assessment techniques that better take into account agglomeration economies and regional effects (see Teulings, Ossokina and De Groot, 2014).

What are appropriate public transport policies depends on whether or not new pricing instruments for passenger cars are introduced. For example, the introduction of road pricing makes differentiated (in space and time) public transport fares more desirable (with higher peak fares). Moreover, the benefits of public transport investment depend on which car pricing instruments are introduced.

\subsection{Complementary labor market policies}

Although detailed analysis of such policies are outside the scope of this paper, some countries have developed labor market policies that have strong - and sometimes very adverse - implications for the transport sector.

One example is the large implicit subsidy many European countries provide to company cars (see Guttierez and Van Ommeren, 2011; De Borger and Wuyts, 2011). This is illustrated in Figure 4 (Harding, 2014) where the proportion of the taxed benefits of a company car is reported for OECD countries. In many EU member countries less than $50 \%$ of the (private) benefits of a company car is taxed. Although high labor taxes are probably the main reason for their existence, subsidies for company cars are often defended on the basis of their presumed environmental benefits. Company cars are on average more fuel efficient than the average car in the stock, because they are much younger than the average car and benefit often from specific fuel efficiency standards.

in Hasselt (a town in Flanders) and found that some 15\% of the new bus users would have used the car when public transport was not free. 
However, the subsidies are well known to raise car traffic, mainly (but not exclusively) for commuting purposes, and they distort car ownership decisions. Moreover, the environmental benefits are highly doubtful, as the increase in kilometers compensates for the lower emissions per kilometer and as there are already covered by other environmental policies in place (Copenhagen Economics (2010)). The estimated welfare cost of subsidies to company cars is therefore large, and a drastic reduction of the implicit subsidy has been suggested to raise efficiency of the transport sector (see the references given above).

Another related example is the tax deductibility of commuting expenses in many EU-countries. This deductibility can be justified under some conditions once new pricing instruments (road pricing) are introduced, but they reduce welfare at current taxes on car use (Van Dender (2003), De Borger (2009)).

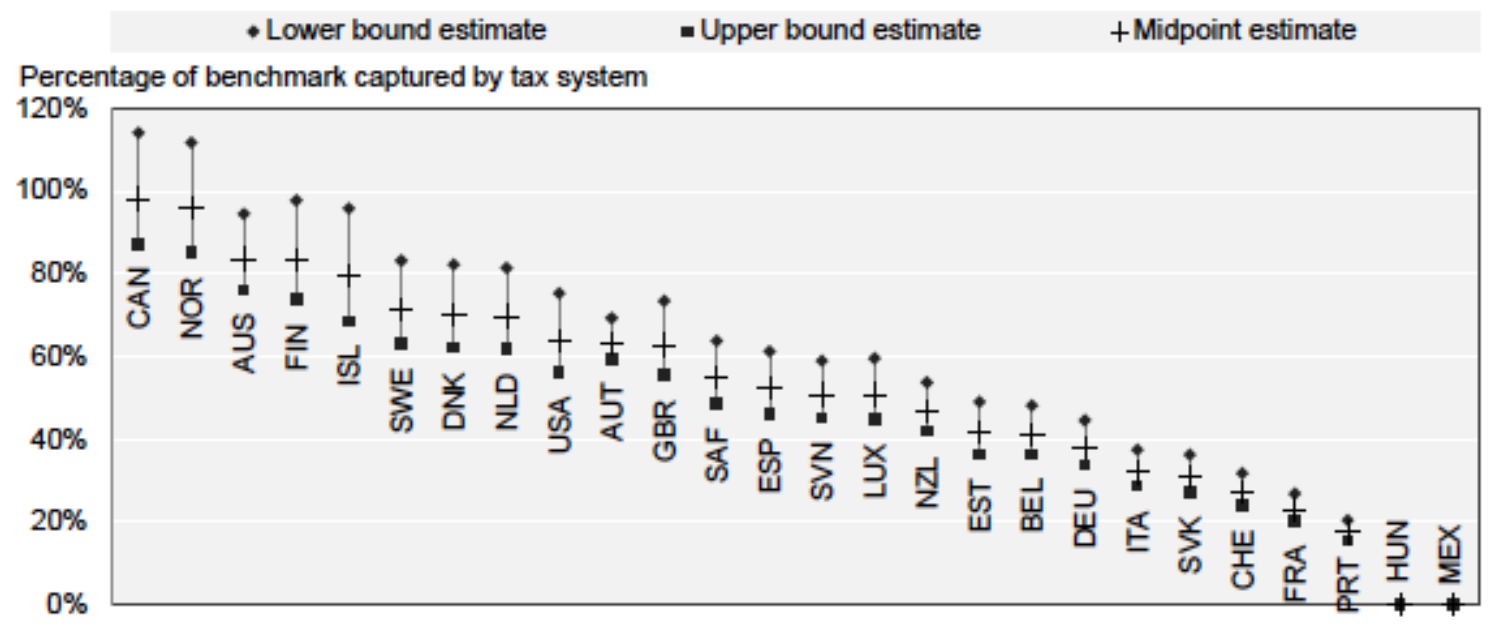

Figure 4. Share of the benefits of a company car that is fixed in 2012 (source: Harding, 2014)

\section{Pricing of trucks}

In this section, we turn to pricing policies for road freight transport. The share of trucks in freight transport has been growing over the years to $72 \%$, while the rail share has been decreasing slowly to $17 \%$ in $2012^{21}$, while the share of rail has been slowly decreasing. There are two developments we want to highlight. First, the way trucks are charged is changing fast in the EU; second, the EU is pursuing a vigorous policy to decrease the modal share of road freight transport.

\subsection{From fuel taxes to distance charges}

Almost all EU countries charge excises for diesel fuel used by trucks. Because trucks can cover 1000 to 2000 kilometer with a single tank, countries or regions engage in fuel tax competition. The difference in distances covered implies that tax competition is much more important for trucks than for cars. Evers, de Mooij and

${ }^{21}$ Inland freight activity by mode (source: EU , 2014) 
Vollebergh (2004) studied a panel data set for 17 countries (1978-2001) and estimated how countries react to the diesel excise taxes set in neighbouring countries. They found strong evidence of tax competition: when neighbouring countries increase their fuel excise tax by 10\%, an average EU-country increases its tax by 2 to $3 \%$. Within the EU, some smaller countries chose a strategy of low excise taxes to make international hauliers fuel up in their country; Luxemburg is the most obvious example. This behavior has brought the EU to negotiate a minimum level of excise taxes. In 2012, Germany charged an excise of 0,589 \$/liter, while Luxemburg charged the EUminimum of $0,343 \$$ /liter (IEA, 2013). Evers et al. (2004) further also found that the imposition of minimum tax rates has increased overall excise levels, but it has not decreased the intensity of tax competition. Next to diesel excise taxes, EU member states that did not use tolls on their motorways, were allowed to charge additional fees for road use in the form of a vignette (annual, monthly, daily fixed payment per vehicle). This Euro-vignette had to be non-discriminatory, and it was to be based on the actual infrastructure costs ${ }^{22}$ (see Vierth and Schleusser, 2012). Over time its use was extended so that it can also charge for environmental costs.

Technological progress in charging techniques implied that several countries facing through traffic wanted to introduce distance-based charging. Switzerland (not an EU member) replaced its vignette system in 2001 by a kilometer charge that charged trucks much more than before. The neighbouring countries followed: Austria (a transit country parallel to Switzerland) in 2004, Germany in 2005 (although it wanted to start earlier), the Czech Republic in 2007, Slovakia in 2010 and Poland in 2011. Other countries (for example, Belgium) are preparing distance charges too. Some other EU countries had already a tolling system for most of their motorways (France, Italy, Spain). This mainly serves to cover infrastructure costs, with the restriction in France that an un-tolled alternative (viz., national roads) has to be available.

The different charging systems in place for trucks in Europe (see Figure 5 for the situation in 2012) show a clear pattern, in that the introduction of distance charges were geographically strongly correlated. The member states in the center of Europe tend to use distance-based charges, while states further from the center use vignettes or no charges at all (apart from fuel taxes). This is no surprise, because countries still engage in tax competition and react to the introduction of higher kilometer charges in neighbouring countries (De Borger, Proost and Van Dender (2005)).

\footnotetext{
${ }^{22}$ See directive 1999/62/EC followed by directives 2006/38/EC and 206/103/EC.
} 


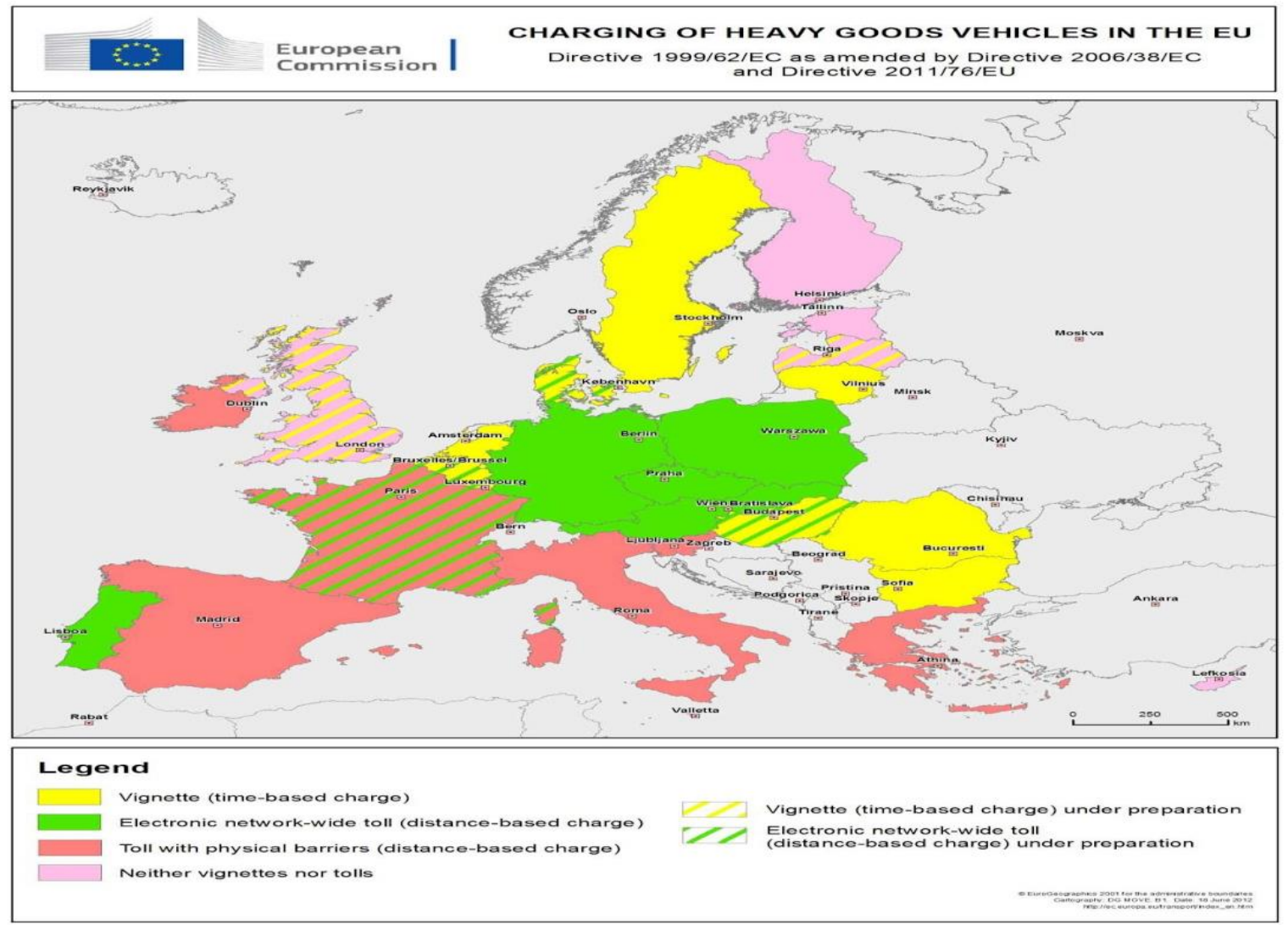

Figure 5. Different types of truck pricing in EU (source: EC.)

There are four interesting features to note about the transition from vignettes to distance-based charges. First, all distance-based charging generated a lot more revenues than the vignettes they replaced. In Germany, distance charge revenues were 6.5 times larger than the revenues of the Eurovignette (Vierth and Schleusser, 2012). One of the reasons the vignette revenues lagged behind was that it is a system common to five countries, and unanimity is required for updates to capture inflation and to include environmental costs. Second, the distance charging schemes discriminate much more in function of conventional air pollution than do the Eurovignette systems. Third, as noted in the theoretical literature, kilometer charges imply the risk of tax exporting to foreign users (see Kanbur and Keen (1993), De Borger, Proost and Van Dender (2005)). 


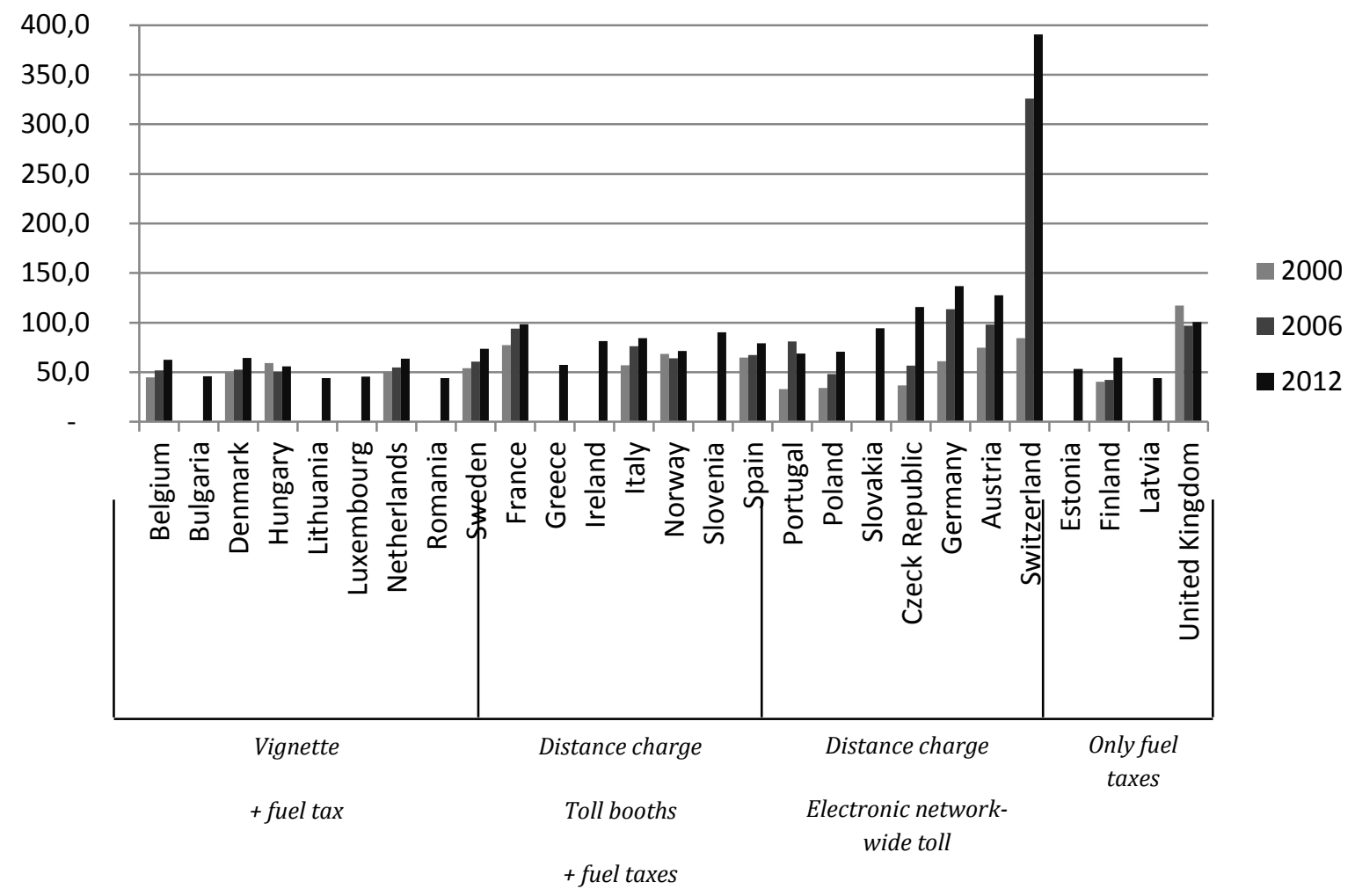

Figure 6. Total charges in Euro for a standard domestic haul of $400 \mathrm{~km}$ by a 40 ton truck. Charging policy as of 2012 (data taken from ITF, 2013 - regrouped by Mandell and Proost (2015))

If one compares the distance charges between countries, one finds that Switserland charges 10 times more per kilometer than most other EU-countries. Austria also charges significantly more than the others. Of course, although infrastructure costs may be higher in these countries, the main reason is the strategic position of Switzerland as a transit country. Austria is also a transit country but it is a slightly less interesting route, and it is bounded by the EU cap on truck charges, while Switserland is not. Finally, note that the transaction costs associated with a distance-based system vary between 10 and $20 \%$ of the revenues (see Hamilton and Eliasson, 2013), probably much larger than those for fuel excise taxation.

Figure 6 gives the total charges and taxes for a standard domestic haul in several OECD countries. The charges have increased strongly over the last 10 years. The countries with the lowest charges are those countries that have no tolls or distance charges ${ }^{23}$.

\footnotetext{
${ }^{23}$ Ireland (high fixed charges per truck) and UK (high fuel charges) are the exceptions.
} 


\section{The transition from fuel taxes to kilometer-based charges.}

Mandell and Proost (2015) analyse this transition and find that distance charges are very contagious, but that the replacement of diesel taxes by distance charges is not necessarily welfare improving. The outcome will depend on the availability of additional instruments to tax diesel cars and on whether or not the distance charges are finely tuned to external costs.

Consider first the case where diesel excises are used only for trucks, while cars are taxed using other instruments. In the Nash equilibrium, the diesel taxes can then be lower or higher than the external and infrastructure costs of trucks. The taxes will typically be low in countries of equal size with intensive tax competition. When countries differ in size, a low tax results in the small country, confirming results from the literature (Kanbur and Keen, 1993). It is found that when distance charges also become available and their implementation costs are low, then all countries will adopt distance charges for trucks, and fuel taxes are driven to the bottom. The distance charges will all be higher than the external cost. One expects this to be the case, for example, when there is tolling on a serial corridor used by international traffic and where several governments tax traffic within their jurisdiction. As long as the different governments do not fully incorporate the consumer surplus of international traffic, tolls will be larger than the external cost (De Borger, Dunkerley and Proost, 2007) ${ }^{1}$. Moving from diesel taxes to distance charges can therefore be welfare-decreasing.

Consider next the case where fuel taxes are used to tax not only trucks but also to tax diesel cars. If there are no distance charges, the fuel tax will have to balance the optimal taxation of diesel cars and trucks. As only one instrument is used, the tax will be a weighted average of external costs of diesel cars, trucks and margins on international trucking. Tax competition can again increase or decrease the tax, but diesel use by cars is typically less vulnerable to tax competition. The result will be that the diesel tax in one country reacts less strongly to tax changes in a neighbouring country. Introduce now distance charges for trucks. Both countries will use distance charges and fuel excises. The sum of distance charges and fuel excises will be higher than the external cost for trucks, and the diesel tax tends to be lower than the external costs of diesel cars. Again there is no guarantee that the introduction of distance charges improves the welfare effects of pricing.

The EU has to some extent anticipated that the introduction of distance charges in transit countries may lead to charges that are too high. The EU constitution does not allow discriminatory charges, but this is no guarantee against too high truck charges in transit countries. It therefore requires that distance charges for trucks have to be based on external costs, but the estimation of external costs requires a lot of interpretation. For this reason, the distance charges are capped by the EU on the basis of average infrastructure costs. When road congestion is an important external cost, and one has constant returns to scale in infrastructure extension, this cap can guarantee efficient pricing. This is due to the combination of two mechanisms. First, when tolls equal the marginal external congestion costs, they will pay for road infrastructure costs in the presence of constant returns to scale in road capacity. The second mechanism is that a government that wants to maximize the benefits for its local users and cannot discriminate against foreigners, will implement the federally optimal policy. Adding the obligation to spend the toll revenues on road infrastructure forces the local government to implement optimal policies. So thereis even no need anymore for the federal regulator to know the external congestion costs (Van der Loo and Proost, 2013). 
Finally, note that the distance charges for trucks have up to now mainly be used as a simple distance toll with some environmental differentiation. They can become much more effective when they are more closely geared to the external costs of congestion, local air pollution and accidents.

\subsection{Complementary policies}

The EU policy line for freight contains ambitious modal share objectives. This requires additional investments but also better integration of international rail freight operations. Progress on the integration of rail freight operations (interoperability, etc.) has been slow. As observed before, many of the investment projects that were considered a priority did not pass the CBA test (Proost et al, 2013).

The introduction of more competition in rail freight services by the vertical divestiture between infrastructure and operations has been slow as well, despite the fact that the expected welfare benefits from increased competition are likely to outweigh the extra transaction costs. The latter are estimated to amount to just $2-3 \%$ of total costs (Merkert, Smith and Nash (2012)).

\section{Conclusion}

The EU has succeeded in making member states accept external costs as a basis for transport tax policies. As the available policy instrument set was up to now mainly restricted to fuel taxes and fixed taxes for vehicle ownership, suboptimal policy developments were the result. There has been a too large emphasis on climate issues leading to a strong focus on fuel saving and on development of alternative fuels. These have eroded the fuel tax base and the effectiveness of fuel taxes to address road traffic externalities, particularly congestion.

With the rising congestion pressures on urban roads and public transport systems, Europe needs a fiscal reform in the transport sector. The reform consists in replacing, to a large extent, the fuel tax instrument by a set of distance taxes that vary by place, time and type of vehicle. New, potentially better instruments are being introduced for trucks under the form of distance charging and for cars under the form of congestion charging. Distance charging for trucks is at present mainly geared to revenue and environmental objectives and is therefore lacking the right focus. Congestion charging for cars has the correct emphasis on congestion but needs to work on its public acceptance and on its transaction costs. Dealing with congestion will be necessary if one wants cities to continue to be the engine of economic growth. 


\section{References}

Alcott, H. and M. Greenstone, 2012, Is there an energy efficiency gap?, NBER WP 17766.

Anas, A. and R. Lindsey, 2011, Reducing urban road transportation externalities: road pricing in theory and in practice, Review of Environmental Economics and Policy 5(1), 66-88.

Barla, P. and S. Proost, 2012, Energy efficiency policy in a non-cooperative world, Energy Economics 34(6), 22092215.

Basso, L.J. and H.E. Silva, 2014, Efficiency and substitutability of Transit subsidies and other urban transport policies, American Economic Journal: Economic Policy 6 (4), 1-33.

Borjesson M., C-M Fung, S.Proost, 2015, Should busses be subsidized in Stockholm?, mimeo

Brown, Stephen P.A., and Hillard G. Huntington, 2010, Estimating US Oil Security Premiums, Discussion Paper 1005 (Washington: Resources for the Future).

Calthrop, E. and S. Proost, 2003, Environmental pricing in transport, Ch. 29 in Henscher D.A.and K.J.Button (eds), Handbook of Transport and the environment, Elsevier.

Crist, C., 2012, Electric Vehicles Revisited - Costs, Subsidies and Prospects, ITF Discussion Paper 2012-03 (http://www.internationaltransportforum.org/itrc/DiscussionPapers/DP201203.pdf).

Copenhagen Economics, 2010, Company car taxation, Working Paper 22.

D'Haultfoeuille, X., Givord, P. and X. Boutin, 2013, The Environmental Effect of Green Taxation: the Case of the French "Bonus/Malus", Economic Journal, doi:10.1111/ecoj.12089, Forthcoming

De Borger, B., 2009, Commuting, congestion tolls and non-competitive labour markets: optimal congestion pricing in a wage bargaining model. Regional Science and Urban Economics 39 (4), 433-448.

De Borger, B., Dunkerley, F. and S. Proost, 2007, Strategic investment and pricing decisions in a congested transport corridor, Journal of Urban Economics 62, 294-316.

De Borger, B. and I. Mayeres, 2007, Optimal taxation of car ownership, car use and public transport: Insights derived from a discrete choice numerical optimization model, European Economic Review 51, 1177-1204.

De Borger, B., Proost, S. and K. Van Dender, 2005, Congestion and tax competition in a parallel network, European Economic Review 49, 213-240.

De Borger, B. and S. Proost, 2012, A political economy model of road pricing. Journal of Urban Economics, 71(1), 79-92.

De Borger, B. and S. Proost, 2012, Transport policy competition between governments: a selective survey of the literature, Economics of Transportation, 1, 35-48.

De Borger, B. and S. Proost, 2013, Traffic externalities in cities: the economics of speed bumps, low emission zones and city bypasses, Journal of Urban Economics, 76, 53-70.

De Borger, B. and B. Wuyts, 2011, The tax treatment of company cars, commuting and optimal congestion taxes, Transportation Research B 45, 1527-1544. 
Dechezlepretre A. and D.Popp, 2014, Fiscal and Regulatory Instruments for Clean Technology, paper presented at the C Ifo/EC/IMF/PBL Conference on Energy Tax and Regulatory Policy in Europe: Reform Priorities and Research Needs (nov 13-14, CES-IFO

Eliasson, J., Hultzkranz, L., Nerhagen, L. Smidfelt and L. Rosqvist, 2009, The Stockholm congestion charging trial 2006: Overview of effects, Transportation Research A 43 (3), 240-250.

Eliasson, J., 2014, The Stockholm congestion charges: an overview, CTS discussion paper 2014/7

Eliasson, J. and S. Proost, 2015, How sustainable is sustainable transport?, Transport Policy 37, 92-101.

European Commission - Directorate-General for Energy and Transport, 2006. Keep Europe moving. Sustainable mobility for our continent, Brussels.

European Commission - Directorate-General for Mobility and Transport, 2011. White paper. Roadmap to a Single European Transport Area - Towards a competitive and resource-efficient transport System, Brussels.

European Commission,; 2014, EU transport in Figures, statistical pocketbook, ISBN 978-92-79-375064doi:10.2832/63317

Geilenkirchen, E, Renes G. and J. van Meerkerk, 2014, Vergroening van de aanschafbelasting voor personenauto's. Effecten op de verkoop van zuinige auto's en de CO2-uitstoot, PBL report 970, The Hague.

Grigolon L., Reynaert, M. and F. Verboven, 2014, Consumer valuation of fuel costs and the effectiveness of tax policy: Evidence from the European car market, CES Discussion Paper 14.34.

Guttiérez-i-Puigarnau, E. and J. van Ommeren, 2011, Welfare effects of distortionary company car taxation. International Economic Review 52 (4), 1105-1122.

Hamilton, C. and J. Eliasson, 2013, Costs and benefits of the European directive on road tolling interoperability, Transportation Research C.

Harding, M., 2014, Personal Tax Treatment of Company Cars and Commuting Expenses: Estimating the Fiscal and Environmental Costs, OECD Taxation Working Papers, No. 20, OECD Publishing. http://dx.doi.org/10.1787/5jz14cg1s7vl-en.

Huse, C., 2014, Fast and Furious (and dirty): how asymmetric regulation may hinder environmental policy, paper presented at the Conference on the future of fuel taxes, CTS-KTH Stockholm September 2014.

ICCT, 2013, EU - vehicle market pocket book.

ITF, 2013, Hylen, B.,Kauppila J., Chong E., Road Haulage Charges and Taxes, DP ITF, 2013-08.

Kanbur, A. and M. Keen, 1993, Jeux sans frontières: tax competition when countries differ in size, American Economic Review 83, 877-892.

Kilani, M., Proost, S. and S. van der Loo, 2014, Road pricing and public transport pricing reform in Paris: complements or substitutes. Economics of Transportation, forthcoming.

Kilian L., 2008, Exogenous oil shocks: how big are they and how much fo they matter for the US economy?, The Review of Economics and Statistics, 90,2, 216-240. 
Mandell S. and S. Proost, 2014, Contagious truck distance charges drive fuel taxes to the bottom, CTS KTH Stockholm, mimeo.

Mayeres, I. and S. Proost, 2013, The taxation of diesel cars in Belgium - revisited. Energy Policy, 54, 33-41.

Merkert, R., Smith A. and C. Nash, 2012, The measurement of transaction costs - evidence from European Railways, Journal of Transport Economics and Policy, 46(3), 349-366.

Munk-Nielsen, A., 2014, Diesel cars and Environmental Policy, Paper presented at the at the Conference on the future of fuel taxes, CTS-KTH Stockholm September 2014

Parry,I. Heine, D., Lis E. and S. Li, 2014, Getting Energy Prices Right - from Principle to Practice, IMF.

Parry, I and K. Small, 2005. Does Britain or the United States have the right gasoline tax, American Economic Review 95, 1276-1289.

Parry, I and K.A. Small, 2009, Should urban subsidies be reduced?, American Economic Review, vol. 99 (3), pp. 700724

Parry, I., Evans D., and W.E. Oates, 2014, Are energy efficiency standards justified?, Journal of Environmental Economics and Management, 67,104-125

Proost, S. and K. Van Dender, 2001, The welfare impacts of alternative policies to address atmospheric pollution in urban road transport, Regional Science and Urban Economics 31 (4), p. 383-411.

Proost, S. and K. Van Dender, 2012, Energy and environment challenges in the transport sector. Economics of Transportation, 1, 77-87.

Proost, S., Dunkerley, F., Van der Loo, S., Adler, N., Bröcker, J. and A. Korzhenevych, 2013, Do the selected trans European transport investments pass the cost benefit test?. Transportation, forthcoming.

Teulings, K., Ossokina, I. and H. De Groot, 2014, Welfare Benefits of Agglomeration and Worker Heterogeneity, CES-IFO working paper, $n^{\circ} 4939$

Tirachini, A., Hensher, D.A. and S.R. Jara-Díaz, 2010, Comparing operator and users costs of light rail, heavy rail and bus rapid transitover a radial public transport network, Research in Transportation Economics 29, $231-242$.

Van Dender, K., 2003, Transport taxes with multiple trip purposes. Scandinavian Journal of Economics 105, 295310.

Van der Loo, S. and S. Proost, 2014, The European road pricing game: how to enforce optimal pricing in high-transit countries under asymmetric information, Journal of Transport Economics and Policy, forthcoming

van Meerkerk, J., Renes, G., and G. Ridder, 2014, Greening the Dutch car fleet: the role of differentiated sales taxes, PBL Working Paper, The Hague

Wolff, H. and L. Perry, 2011, Keep your clunker in the suburb: low emission zones and adoption of green vehicles, Discussion Paper, University of Washington

Van Goeverden, C., Rietveld, P., Koelemeijer, J. and P. Peeters (2006), Subsidies in public transport, European Transport 32, 5-25 
Vierth, I. and H.Schleusser, 2012, Impacts of different environmentally differentiated truck charges on mileage, fleet composition and emissions in Germany and Sweden, CTS working paper 2012:22.

Vollebergh H. and E. van der Werf,2014, The role of standards in eco-innovation: Lessons for policymakers, Review of Environmental Economics and Policy 8 (2), 230-248.

Weismann, P., 2013, The Genesis of the Eurovignette directive, European Transport \Trasporti Europei, 53, Paper $\mathrm{n}^{\circ} 2$, ISSN 1825-3997.

Weitzman, M., 1974, Prices versus Quantities, Review of Economic Studies 41 (4), 477-491. 


\section{APPENDIX TO TABLE 1}

Unless otherwise noted, all external cost information is based on the EU Handbook on External Costs of Transport (2014).

\section{External climate cost (Tables 35, 36, 38 in the Handbook)}

A CO2 damage cost of 25 euro per ton was used instead of the 90 euro per ton (based on avoidance costs) of the EU Handbook. The former estimate is more in line with the cost of reducing CO2 in other sectors of the economy. The category "urban" of the Handbook corresponds to "urban" and "local" in Table 1, while the categories "rural" and "motorways" in the Handbook are classified as "medium to long distance" in Table 1. The values of climate costs for type Euro-5 vehicles (cars, trucks) of medium size are shown in the table. For air transport, the values for medium flight distance $(1000-1500 \mathrm{~km})$ are used.

\section{External air pollution and noise cost (Tables 17, 20, 28 in the Handbook)}

The calculation method focuses on the monetary valuation of the explicit impact that the emissions have on human health, environment, and economic activity. The effect of emissions is constructed taking into account diffusion, dose-effect relationships as well as valuation of statistical years of life lost and health impacts. The values are obtained by adding the air pollution and noise cost. We use the values of Euro- 6 and medium-sized vehicles (cars, buses, trucks) in our table. Using the bottom-up approach, the noise costs vary greatly according to time of day and density of traffic. We take the upper bound of noise costs, which are the noise costs of thin traffic at night, taken from the 2008 version of the Handbook updated for the change in overall price levels in the EU.

Again, the category "urban" in the Handbook corresponds to "urban" and "local" in our Table 1, while the categories "rural", "suburban" and "motorways" in the Handbook are classified as "medium to long distance" in our Table 1.

\section{External accident cost (Table 12 in the Handbook)}

External accident costs are those social costs of traffic accidents, which are not covered by risk oriented insurance premiums. Therefore, the level of external costs depends on the level of accidents and on the insurance system (on whether there is experience rating or not, and on what is covered by insurance). The most important accident cost categories are medical costs, production losses, material damages, administrative costs, and the so called risk value as a proxy to estimate pain, grief and suffering caused by traffic accidents in monetary values. Mainly the latter is not covered properly by the private insurance systems. The values are corrected for underreporting of the number of injuries in some EU countries.

The categories "car" and "HGV" in the Handbook correspond to "car" and "trucks" in our Table 1 respectively. "Motorway" and "other non-urban roads" are classified as "medium to long distance" in our Table 1.

\section{External marginal congestion cost (Table 9 in the Handbook)}

The external cost is the additional cost imposed by a user of the road network on all other users of the road network. The EU handbook estimates of congestion costs are derived from the UK estimates based on the aggregated approach of the FORGE model, using nominal GDP per capita and the average exchange rate between euro and the British Pound for 2010. The FORGE model distinguishes several congestion bands based on the 
volume to capacity ratio, but no EU data on the traffic shares in each bands are available. So instead of averages across congestion bands or road and area type, we give ranges of the external congestion costs.

The categories "urban- main roads, other roads" and "metropolitan- main roads, other roads" in the Handbook

correspond to "urban" in our Table 1, while the categories "rural" and "metropolitan- motorways" in the Handbook are classified as "medium to long distance" in our Table 1.

Wear and tear infrastructure cost (Tables 48 and 51 in the Handbook)

Marginal road infrastructure costs correspond to the increase in road maintenance and repair expenditures that are induced by higher traffic levels. Heavier vehicles tend to cause more damage to the roads, whereby the degree to which an increase in weight leads to higher damage follows a power law.

The categories "other trunk roads" and "other roads" in the Handbook correspond to "urban" in our Table 1, while the category "motorways" in the Handbook is classified as "medium to long distance" in our Table 1. 
Copyright (c) 2015 @ the author(s). Discussion papers are in draft form. This discussion paper is distributed for purposes of comment and discussion only. It may not be reproduced without permission of the copyright holder. Copies of working papers are available from the author. 